\title{
EFEKTIVITAS FELDENKRAIS EXERCISE LEBIH BAIK DARIPADA CORE STABILITY EXERCISE TERHADAP PENINGKATAN KEMAMPUAN FUNGSIONAL PADA PASIEN NYERI PUNGGUNG BAWAH NON SPESIFIK KRONIS
}

\author{
Maulida Rohmah Fauziah', Luh Putu Ratna Sundari², Wahyuddin ${ }^{3}$, Ketut Tirtayasa ${ }^{4}$, Ni \\ Nyoman Ayu Dewi ${ }^{5}$, Ni Made Swasti Wulanyani ${ }^{6}$ \\ ${ }^{1}$ Program Studi Magister Fisiologi Keolahragaan, Universitas Udayana, Denpasar \\ ${ }^{2,4}$ Departemen Ilmu Faal, Fakultas Kedokteran, Universitas Udayana, Denpasar \\ ${ }^{3}$ Fakultas Fisioterapi, Universitas Esa Unggul, Jakarta \\ ${ }^{5}$ Departemen Biokimia, Fakultas Kedokteran Universitas Udayana, Denpasar \\ ${ }^{6}$ Departemen Psikologi, Fakultas Kedokteran Universitas Udayana, Denpasar
}

E-Mail : maulida.fauziah@ymail.com

\begin{abstract}
ABSTRAK
Latar Belakang: Keluhan nyeri punggung bawah non spesifik kronis menyebabkan keterbatasan dalam beraktivitas sehari-hari. Latihan yang paling banyak digunakan untuk mengatasinya adalah core stability exercise, namun hasilnya tidak konsisten dan terbatas. Tujuan penelitian ini yaitu untuk membuktikan bahwa Feldenkrais exercise lebih efektif dalam meningkatkan kemampuan fungsional pada pasien NPB non spesifik kronis. Materi dan Metode: Penelitian ini mengikutsertakan 20 pasien NPB non spesifik kronis di Klinik Halmahera Medika Bandung yang memenuhi kriteria inklusi. Penelitian ini merupakan penelitian eksperimental dengan rancangan pre and post test control group design. Subjek dibagi ke dalam 2 kelompok, masingmasing 10 orang secara acak. Kelompok I mendapat perlakuan Feldenkrais exercise sedangkan kelompok II mendapat perlakuan core stability exercise selama 8 minggu. Kemampuan fungsional diukur menggunakan Modified Oswestry Disability Index sebelum intervensi dan setelah intervensi selama 8 minggu. Hasil: Hasil perbandingan persentase ODI sebelum dan setelah dalam masingmasing kelompok menunjukkan perubahan yang signifikan $(\mathrm{p}=0,005 ; \mathrm{p}=0,005)$. Sedangkan hasil perbandingan selisih perubahan ODI antara ke dua kelompok menunjukkan terdapat perbedaan yang signifikan dengan Kelompok I lebih banyak meningkatkan kemampuan fungsional daripada Kelompok II $(\mathrm{p}=0,009)$. Kategori disabilitas di Kelompok I juga lebih rendah daripada kategori disabilitas di kelompok CSE. Kesimpulan: Feldenkrais exercise lebih efektif daripada CSE dalam meningkatkan kemampuan fungsional.
\end{abstract}

Kata kunci: Nyeri Punggung Bawah, Feldenkrais, Core Stability Exercise, Awareness Through Movement, Oswestry Disability Index.

\section{FELDENKRAIS EXERCISE EFFECTIVITY IS BETTER THAN CORE STABILITY EXERCISE ON IMPROVING FUNCTIONAL CAPACITY OF CHRONIC NON SPECIFIC LOW BACK PAIN PATIENTS}

\section{ABSTRACT}

Background: Chronic non specified low back pain (CNLBP) has caused activity limitations. The most widely use exercise to overcome it is core stability exercise but the results are inconsistent and limited.Objective of this study is proving that Feldenkrais Exercise is more effective than CSE 
on improving functional capacity of CNLBP patients. Material and Method: This research included 20 CNLBP patients at Halmahera Medika Clinic Bandung that met inclusion criterias. This research is an experiment research design with pre and post-test control group design. Subjects were divided into two groups, 10 subjects each group, randomly. Group I performed Feldenkrais exercise and group II performed core stability exercise for 8 weeks. Functional capacity was measured by Indonesian Version of Modified Oswestry Disability Index before and after 8 weeks intervention. Result: The comparison test results show that there are significant changes on pre and post ODI percentage in each group $(\mathrm{p}=0,005 ; \mathrm{p}=0,005)$. Meanwhile, the comparison result between two groups ODI percentage difference shows that there is a significant difference between them with Feldenkrais exercise is better than CSE on improving functional capacity $(p=0,009)$. Disability category in Feldenkrais group is lower than in CSE group. Conclusion: Feldenkrais exercise is more effective than core stability exercise on improving functional capacity of CNLBP patients.

Keywords: Low Back Pain, Feldenkrais, Core Stability Exercise, Awareness Through Movement, Oswestry Disability Index.

\section{PENDAHULUAN}

Setiap individu diperkirakan pernah mengalami nyeri punggung bawah (NPB) dalam fase hidupnya. NPB merupakan penyebab utama disabilitas dan berada di peringkat keenam beban global secara keseluruhan di negara maju maupun berkembang. ${ }^{1}$

NPB adalah suatu keluhan nyeri yang dirasakan diantara batas bagian rusuk bawah sampai lipatan pantat dan terkadang disertai keluhan neurologis pada anggota gerak bawah. $^{2}$ Sebanyak $62,2 \%$ pasien NPB kronis memiliki NPB non spesifik kronis. Meskipun keluhan NPB non spesifik dapat hilang dalam beberapa minggu tanpa penanganan tetapi pada beberapa kasus, nyeri menetap selama lebih dari 12 minggu dan berkembang menjadi NPB non spesifik kronis. Individu dengan nyeri kronis ini cenderung melakukan kompensasi gerak, substitusi dan menghindari gerak tertentu yang dianggap memicu nyeri dan membatasi gerak. ${ }^{3}$

Exercise therapy yang paling umum direkomendasikan berdasarkan evidence adalah Core Stability Exercise (CSE). ${ }^{4}$ Latihan ini bertujuan menstabilkan punggung bawah dengan meningkatkan kontrol lumbopelvic dan abdominal melalui aktivasi m. transversus abdominis dan multifidus. ${ }^{5}$ Tetapi, beberapa penelitian mengenai CSE menunjukkan bahwa stabilitas yang diberikan dari latihan ini tidak selalu meningkatkan mobilitas ataupun kemampuan fungsional pasien NPB non spesifik kronis dan meningkatnya kekuatan otot-otot core tidak selalu berbanding lurus dengan peningkatan kemampuan fungsional. ${ }^{6}$

Exercise lain yang mulai banyak digunakan untuk mengatasi NPB non spesifik kronis adalah Feldenkrais exercise. ${ }^{7}$ Metode ini dilakukan menggunakan prinsip Awareness Through Movement (ATM). Prinsip ATM ini membantu meningkatkan kinestesia dan sensitivitas propioseptif yang berperan untuk membentuk mobilitas yang baik. Tujuan prinsip ATM ini untuk meningkatkan body awareness sehingga gerakan yang dilakukan bebas nyeri, efisien serta efektif. Peningkatan awareness ini merupakan awal mula terbentuknya skilled motor function yang mendukung kemampuan fungsional yang optimal dan otomatis. ${ }^{8}$

Hasil penelitian tentang penanganan NPB menunjukkan hasil yang tidak konsisten dan terbatas. ${ }^{9}$ Namun, berdasarkan manfaatmanfaat yang lebih kompleks dari Feldenkrais exercise terhadap pasien NPB non spesifik kronis, maka hal ini menunjukkan bahwa Feldenkrais exercise lebih efektif daripada CSE dalam meningkatkan kemampuan fungsional pasien NPB non spesifik kronis.

\section{METODE PENELITIAN}

Penelitian menggunakan desain eksperimental pre and post-test dengan 
Kelompok I diberikan Feldenkrais Exercise dan Kelompok II diberikan core stability exercise. Pengukuran kemampuan fungsional diukur menggunakan Modified Oswestry Disability Index versi Indonesia. Penelitian dilakukan di Klinik Utama Halmahera Medika Kota Bandung Jawa Barat, pada Maret - April 2019. Penelitian dilakukan dengan frekuensi 3 kali seminggu yang berlangsung selama delapan minggu. Sampel berjumlah 10 orang di masing-masing kelompok.

\section{HASIL PENELITIAN}

\section{Karakteristik Subjek}

Tabel 1

Karakteristik Subjek Kelompok I dan II Berdasarkan Jenis Kelamin, Usia dan IMT

\begin{tabular}{cccc}
\hline \multirow{2}{*}{ Kategori } & \multicolumn{2}{c}{ Frekuensi (\%) } \\
\cline { 3 - 4 } & & Kelompok & Kelompok \\
I & II \\
\hline Jenis & Laki-laki & $2(20)$ & $3(30)$ \\
Kelamin & Perempuan & $8(80)$ & $7(70)$ \\
Usia & $40-45$ & $1(10)$ & $2(20)$ \\
(tahun) & $46-50$ & $4(40)$ & $6(60)$ \\
& $51-55$ & $1(10)$ & $0(0)$ \\
IMT & $56-60$ & $4(40)$ & $2(20)$ \\
$\left(\mathrm{kg} / \mathrm{m}^{2}\right)$ & Underweight & $0(0)$ & $0(0)$ \\
& Normal & $4(40)$ & $4(40)$ \\
& Overweight & $4(40)$ & $2(20)$ \\
& Obesitas & $2(20)$ & $4(40)$ \\
\hline
\end{tabular}

Pada Tabel 1 berisi distribusi karakteristik subjek yang menunjukkan total subjek penelitian adalah 20 orang $(n=20)$, dengan distribusi tiap Kelompok I dan II berjumlah sepuluh orang (100\%). Kelompok I dan II di dominasi oleh perempuan. Distribusi umur pada Kelompok I di dominasi oleh kelompok usia 46-50 tahun dan usia 56-60. Sementara untuk Kelompok II didominasi oleh rentang usia 46-50 tahun. Distribusi IMT pada subjek Kelompok I didominasi oleh kategori normal dan overweight. Pada Kelompok II didominasi oleh kategori normal dan obesitas.
Tabel 2

Perbandingan Karakteristik Data di antara Ke dua Kelompok Sebelum Perlakuan

\begin{tabular}{cccc}
\hline & \multicolumn{3}{c}{ Rerata \pm SB } \\
Karakteristik & Kelompok & Kelompok & $\mathrm{P}^{\mathrm{a}}$ \\
& $\mathrm{I}$ & $\mathrm{II}$ & \\
\hline $\begin{array}{c}\text { Usia (tahun) } \\
\text { IMT }\left(\mathrm{Kg} / \mathrm{m}^{2}\right) \\
\text { Nyeri }\end{array}$ & $51,1 \pm 7,14$ & $48,5 \pm 5,36$ & 0,369 \\
$\begin{array}{c}\text { Bergerak } \\
(\mathrm{cm})\end{array}$ & $4,88 \pm 0,68$ & $5,1 \pm 0,86$ & 0,536 \\
$\begin{array}{c}\text { Nyeri Berdiri } \\
(\mathrm{cm})\end{array}$ & $4,08 \pm 0,65$ & $4,4 \pm 0,81$ & 0,343 \\
$\begin{array}{c}\text { Nyeri Duduk } \\
(\mathrm{cm})\end{array}$ & $4,58 \pm 1,169$ & $4,89 \pm 1$ & 0,532 \\
\hline $\mathrm{a}=$ Independent Sample t-test, SB= Simpang baku
\end{tabular}

Berdasarkan hasil perbandingan karakteristik data awal penelitian yang terdiri dari usia, IMT, nilai VAS dan nilai ODI sebelum perlakuan di Tabel 2 menunjukkan subjek dalam ke dua kelompok perlakuan memiliki kondisi awal yang sama sebelum perlakuan.

\section{Uji Normalitas dan Homogenitas}

Tabel 3

Hasil Uji Normalitas dan Homogenitas

\begin{tabular}{cccc}
\hline & \multicolumn{2}{c}{ Uji Normalitas } & Uji \\
Variabel & Kelompok & Kelompok & Homogenitas \\
& I & II & $\mathrm{P}^{\mathrm{b}}$ \\
& $\mathrm{P}^{\mathrm{a}}$ & $\mathrm{P}^{\mathrm{a}}$ & \\
\hline $\begin{array}{c}\text { ODI } \\
\text { sebelum } \\
\text { ODI }\end{array}$ & 0,028 & 0,662 & \\
$\begin{array}{c}\text { Setelah } \\
\text { a = Shapiro-wilk test, }\end{array}$ & $\mathrm{b}=$ Leuvene test & \\
\end{tabular}

Pada Tabel 3 berisi hasil uji normalitas pada data nilai ODI sebelum dan setelah perlakuan Kelompok I menggunakan Shapiro-Wilk test menghasilkan nilai $\mathrm{p}<0,05$ sedangkan pada Kelompok II P>0,05. Data dianggap berdistribusi tidak normal, karena sebagian kelompok berdistribusi tidak normal.

Selain itu, pada hasil uji homogenitas pada data nilai ODI sebelum perlakuan masing-masing kelompok, didapatkan hasil $p=0,219(p>0,05)$. Hal ini menunjukkan data bersifat homogen. Maka, uji hipotesis 
dilakukan dengan analisis statistik non parametrik.

\section{Uji Beda Nilai ODI Sebelum dan Setelah Perlakuan di Kelompok I dan Kelompok II}

Tabel 4

Hasil Uji Beda Nilai Kemampuan Fungsional Bahu Sebelum dan Setelah Perlakuan Pada Kelompok I dan II

\begin{tabular}{|c|c|c|c|c|}
\hline Grup & $\begin{array}{c}\text { Sebelum } \\
(\%) \\
\text { Rerata } \pm \text { SB }\end{array}$ & $\begin{array}{l}\text { Setelah (\%) } \\
\text { Rerata } \pm \text { SB }\end{array}$ & $\mathrm{p}^{\mathrm{a}}$ & $\begin{array}{c}\text { Selisih } \\
(\%) \\
\text { Rerata } \pm S \\
\text { B }\end{array}$ \\
\hline I & $\begin{array}{c}41,4 \pm 11,9 \\
3\end{array}$ & $18,4 \pm 11,5$ & $\begin{array}{c}0,00 \\
5\end{array}$ & $23 \pm 6,2$ \\
\hline II & $\begin{array}{c}40,8 \pm 10,3 \\
8\end{array}$ & $26 \pm 10,3$ & $\begin{array}{c}0,00 \\
5\end{array}$ & $14,8 \pm 5,8$ \\
\hline $\mathrm{p}^{\mathrm{b}}$ & 0,796 & & & 0,009 \\
\hline
\end{tabular}

Berdasarkan Tabel 4 yang berisi perbandingan persentase ODI sebelum dan setelah di Kelompok I dan II menunjukkan perbedaan yang signifikan dalam masingmasing kelompok dengan nilai $\mathrm{p}<0,05$ pada ke duanya.

\section{Uji Beda Selisih ODI Setelah Perlakuan Pada Kelompok I dan II}

Pada Tabel 4 menunjukkan hasil uji beda selisih persentase ODI Kelompok I dan II setelah perlakuan. Hasil uji beda selisih setelah perlakuan ke dua kelompok menghasilkan nilai signifikansi $\mathrm{p}=0,009$ $(p<0,05)$ yang berarti terdapat perbedaan selisih nilai ODI setelah perlakuan secara signifikan diantara Kelompok I dan II. Maka, dapat disimpulkan bahwa terdapat perbedaan efektifivitas antara Feldenkrais exercise dengan CSE dalam meningkatkan kemampuan fungsional pasien NPB non spesifik kronis, dimana Feldenkrais exercise meningkatkan kemampuan fungsional lebih baik daripada $C S E$.

\section{Feldenkrais Exercise Meningkatkan Kemampuan Fungsional Pasien NPB Non Spesifik Kronis}

Feldenkrais exercise meningkatkan kemampuan fungsional pasien NPB non spesifik kronis secara signifikan. Feldekrais meningkatkan pengolahan interoseptif, proprioceptif dan kinesthetic awareness. Hal ini membantu meningkatkan aktivasi dari deep core trunk muscles sebagai stabilisator. Bentuk gerakan pada Feldenkrais menargetkan area punggung bawah disertai mobilisasi aktif dan mindfull pada hip joint kemudian diikuti dengan gerakan pada area lumbo-pelvic meningkatkan awareness terhadap aktivasi deep muscle. Mobilitas yang mindful ini menurunkan nyeri, menjadikan duduk dan berdiri lebih nyaman dan percaya diri, peningkatan fleksibilitas fungsional, serta meningkatnya kualitas tidur. ${ }^{10}$

Pada penelitian Marianna et al., tentang pengaruh metode Feldenkrais terhadap kesehatan tulang belakang pada pemain musik orkestra yang mengalami nyeri cervical dan lumbal menghasilkan peningkatan fleksibilas m. harmstring dan punggung bawah, peningkatan kekuatan otot ekstensor trunk, serta fleksibilitas dan daya tahan yang lebih meningkat daripada kelompok kontrol meskipun tidak secara signifikan. Kemudian tinggi badan subjek di Kelompok Feldenkrais meningkat secara signifikan daripada sebelum latihan. Hal ini menunjukkan perubahan postural jangka pendek setelah latihan menjadi erect posture atau postur tegak. Beberapa subjek di kelompok ini juga mengalami penurunan nyeri di anggota gerak dan punggung selama melakukan gerakan. Hasil tersebut menunjukkan bahwa Feldenkrais memliki efek positif terhadap fleksibilitas dan mengurangi spasme otot sehingga tidak mengganggu performa pemain. ${ }^{11}$

\section{Core Stability Exercise Meningkatkan Kemampuan Fungsional Pasien NPB Non Spesifik Kronis}

Hasil penelitian ini menunjukkan CSE meningkatkan kemampuan fungsional pasien NPB non spesifik kronis secara signifikan. CSE berfokus untuk meningkatkan core stability melalui aktivasi deep muscles layer 
yang berfungsi untuk menjaga stabilitas postural seperti $\mathrm{m}$. TrA dan $\mathrm{m}$. Multifidus. Adanya muscle imbalance antara sistem local muscle atau deep muscle dan superficial muscle mengganggu stabilitas spinal saat bergerak.

Menurut Mani et al., gerakan abdominal drawing-in digunakan untuk memfasilitasi dan reedukasi dari mekanisme kontrol neuromuskuler di otot-otot stabilisator lokal. Gerakan ini mengaktivasi TrA. Pada saat gerakan dilakukan, terjadi gerakan kearah dalam dari dinding abdominal bawah bersamaan dengan relaksasi otot-otot yang lebih superfisial. Hal ini ada hubungannya dengan ko-kontraksi involunter dari otot lumbal multifidus. ${ }^{12}$ Aktivitas kontraksi TrA secara involunter berperan penting juga untuk menyediakan stabilisasi. Kestabilan ini menghasilkan mobilitas yang efisien pada ekstremitas yang bergerak, sehingga dapat mengurangi nyeri gerak dan meningkatkan fungsional ekstremitas bawah pada pasien NPB kronis. ${ }^{13}$

\section{Feldenkrais Exercise Lebih Efektif daripada Core Stability Exercise dalam Meningkatkan Kemampuan Fungsional Pasien NPB non Spesifik Kronis}

Hasil perbandingan efektivitas kedua intervensi menunjukkan bahwa Feldenkrais exercise lebih efektif daripada CSE dalam meningkatkan kemampuan fungsional pasien NPB non spesifik kronis. Hal ini dikarenakan pada Feldenkrais eksplorasi gerakan yang perlahan dan mindful meningkatkan aktivasi deep muscle layer area lumbopelvic daripada global muscles. Kemudian, dalam Feldenkrais exercise juga melatih mobilitas di hip joint.

Pada penelitian Prather et al., menunjukkan bahwa pasien NPB perlu mendapatkan latihan mobilitas pada hip joint seperti pada Feldenkrais untuk mengurangi nyeri dan mempermudah gerakan karena disfungsi hip menimbulkan nyeri dan disabilitas yang lebih tinggi pada individu dengan NPB karena karakter hip joint, yang secara anatomis menempel pada regio lumbopelvic ${ }^{15}$. Komponen latihan mobilitas di area sendi hip tidak didapatkan dalam $C S E .^{14}$

Menurut penelitian Mannion et al., kemampuan aktivasi TrA dan Multifidus maupun $\mathrm{m}$. obliques abdominalis pada pasien NPB tidak berhubungan dengan peningkatan kemampuan fungsional. Rigiditas trunk yang dihasilkan dari latihan CSE tidak selalu meningkatkan level aktivitas sehari-hari. Beberapa pasien NPB yang mengalami kekakuan pada trunk tidak mendapatkan hasil yang maksimal pada CSE karena yang diperlukan adalah peningkatan mobilitas pada trunk. ${ }^{15}$

Individu dengan NPB kronis cenderung mengalami movement control impairment atau MCI. ${ }^{16}$ Adanya impairmen tersebut memerlukan latihan tipe motor control seperti Feldenkrais yang meningkatkan tactile sensation atau kinestethic learning dan propioseptive input. Gerakan yang lambat dan berulang meningkatkan kerja memori serta atensi yang volunter. Stimulus ini menstimulasi locus coeruleus (LC-NA) dan mengeluarkan respon phasic mode. Pada phasic mode terjadi pengolahan informasi yang meningkatkan efisiensi respon motorik dalam melakukan aktivitas sehari-hari. ${ }^{17}$

Pada penelitian ini, kelompok Feldenkrais lebih banyak menurunkan kategori disabilitas dibandingkan dengan kelompok CSE. Kategori disabilitas di kelompok Feldenkrais yang awalnya berada dalam kategori disabilitas berat menurun ke disabilitas minimal setelah intervensi. Sedangkan pada kelompok CSE hanya menurun dari disabiltas berat kategori moderat. Penurunan ini berhubungan dengan fear of movement (FOM) yang dialami individu dengan nyeri kronis seperi pada NPB. FOM yang berlebihan menghasilkan peningkatan disabilitas dan menghambat pemulihan NPB akut, subakut maupun kronis.

Fear avoidance model of LBP menjelaskan bagaimana individu dengan NPB akut terjebak dalam siklus nyeri dan disabilitas kronis. ${ }^{18}$ Gerakan pada ATM Feldenkrais yang perlahan dan dibayangkan mampu memutus siklus tersebut karena Feldenkrais sejalan dengan movement-based concept. Hal ini didukung oleh underlying 
mekanisme dari motor control dan motor imagery. ${ }^{19}$

\section{KETERBATASAN PENELITIAN}

Keterbatasan penelitian ini adalah peneliti tidak melakukan pemeriksaan kategori impairmen motor control supaya hasil latihan atau intervensi lebih maksimal.

\section{SIMPULAN}

1. Pemberian Feldenkrais exercise selama 60 menit sebanyak tiga kali seminggu dalam delapan minggu dapat meningkatkan kemampuan fungsional pasien NPB non spesifik kronis.

2. Pemberian core stability exercise selama 60 menit sebanyak tiga kali seminggu dalam delapan minggu dapat meningkatkan kemampuan fungsional pasien NPB non spesifik kronis.

3. Pemberian Feldenkrais exercise lebih efektif daripada core stability exercise dalam meningkatkan kemampuan fungsional pasien NPB non spesifik kronis.

\section{DAFTAR PUSTAKA}

1. Hoy D, March L, Woolf A, Blyth F, Brooks P dan Smith E, et al. 2014. The Global Burden of Neck Pain: Estimates from the Global Burden of Disease 2010 Study. Annals of the Rheumatic Diseases, 73: 1309-1315. [Cited 2018 Sept. 18]. Available from:

https://ard.bmj.com/content/annrheumdis/ 73/6/968.full.pdf

2. Hartvigsen J, Hancock MJ, Kongsted A, Louw Q, Ferreira ML dan Al E. 2018. What Low Back Pain is and Why We Need to Pay Attention. Low Back Pain, 391(10137). [Cited 2018 Sept. 18]. Available from: URL:https://www.thelancet.com/pdfs/jou rnals/lancet/PIIS0140-6736(18)30480X.pdf

3. Iizuka $Y$, lizuka $H$, Mieda $T$, Tsunoda D, Sasaki T dan Tajika T. 2017. Prevalence of Chronic Nonspecific Low Back Pain and Its Associated Factors among Middle-Aged and Elderly People: An Analysis Based on Data from a Musculoskeletal Examination in Japan. Asian Spine Journal, 11(6): 989-997. [Cited 2018 Sept. 18]. Available from: https://www.asianspinejournal.org/journa 1/view.php?doi=10.4184/asj.2017.11.6.98 9

4. Noormohammadpour P, Kordi M, Mansournia MA, Akbari-Fakhrabadi M dan Kordi R. 2018. The Role of A MultiStep Core Stability Exercise Program in the Treatment of Nurses with Chronic Low Back Pain: A Single-Blinded Randomized Controlled Trial. Asian Spine Journal, 12: 490-502. [Cited 2018 Sept. 18]. Available from: https://www.ncbi.nlm.nih.gov/pmc/article s/PMC6002169/

5. Wang XQ, Zheng JJ dan Yu ZW. 2012. A Meta-Analysis of Core Stability Exercise versus General Exercise for Chronic Low Back Pain. PLoS One, 7:17.[Cited 2018 Dec. 1]. Available from: https://www.ncbi.nlm.nih.gov/pmc/article s/PMC3524111/

6. Lederman E. 2010. The Myth of Core Stability. Journal of Bodywork and Movement Therapies, 14(1): 84-98. [Cited 2018 Sept. 18]. Available from: https://www.bodyworkmovementtherapie s.com/article/S1360-8592(09)00093$\mathrm{X} / \mathrm{pdf}$

7. Mohan V, Paungmali A, Sitilertpisan P, Henry LJ, Mohamad NB dan Kharami NNB. 2017. Feldenkrais Method on Neck and Low Back Pain to the Type of Exercises and Outcome Measurement Tools: A Systematic review. Polish Annals of Medicine, 24(1): 77-83. [Cited 2018 Dec. 1]. Available from: https://www.sciencedirect.com/science/ar ticle/pii/S1230801316300492

8. Paolucci T, Zangrando F, Iosa M, De A, Marzoli C, Piccinini G, et al. 2016. Improved Interoceptive Awareness in Chronic Low Back Pain: A Comparison of Back School versus Feldenkrais Method. Disability Rehabilitation, 39(10):994-1001. [Cited 2018 Sept. 18]. 


\section{Available}

from:

https://www.ncbi.nlm.nih.gov/pubmed/27 215948

9. Wand BM, Parkitny L, O'Connell NE, Luomajoki $\mathrm{H}$, McAuley JH, Thacker M, et al. 2011. Cortical Changes in Chronic Low Back Pain: Current State of the Art and Implications for Clinical Practice. Manual Therapy, 16: 15-20. [Cited 2018 Sept. 18]. Available from: https://www.bodyinmind.org/wpcontent/uploads/Wand-et-al-2010-MANTHER-cortical-changes-in-painreview.pdf

10. Palmer CF. 2017. Feldenkrais Movement Lessons Improve Older Adults' Awareness, Comfort, and Function. Gerontology and Geriatric Medicine Journal. [Cited 2018 Sept. 18]. Available from:

https://www.ncbi.nlm.nih.gov/pmc/article s/PMC5560512/

11. Marianna B, Caterina F, Agnese V, Giovanni C, Giuseppe B, Andrea F, et al. 2012. Influence of Feldenkrais Method on Spine Health in Professional Orchestral Musicians: Pilot Study. Journal of Sport Sciences and Law, 5 (2). [Cited 2018 Sept. 18]. Available from: https://iris.unipa.it/retrieve/handle/10447/ 73360/72093/30_MariannaBellafiore_22012\%28141-155\%29.pdf

12. Mani P, Rajasekaran B, dan Habib H. 2016. Abdominal Drawing in Maneuver: Effect on Gait Parameters and Pain Reduction in Patients with Chronic Low Back Pain. International Journal of Physiotheraphy, 3(4): 473-477. [Cited 2019 Mar. 11]. Available from:

https://pdfs.semanticscholar.org/e179/4ce 51fdb82aed2032708dd7dd122b65820c5. pdf

13. Slosberg M. 2009. Core Stabilization Strategies: Abdominal Hollowing vs. Bracing. Dynamic Chiropractic, 27(21):1-5. [Cited 2018 Dec. 1]. Available from:

https://www.dynamicchiropractic.com/m pacms/dc/article.php?id=54160
14. Prather H, Cheng A, Steger-May K, Maheshwari V, Dillen LV. 2017. Hip and Lumbar Spine Physical Examination Findings in People Presenting With Low Back Pain, With or Without Lower Extremity Pain. Journal of Orthopaedic and Sports Physical Therapy, 47(3): 163172. [Cited 2018 Dec. 20]. Available from:

https://www.researchgate.net/publication/ 313353227_Hip_and_Lumbar_Spine_Ph ysical_Examination_Findings_in_People _Presenting_With_Low_Back_Pain_Wit h_or_Without_Lower_Extremity_Pain

15. Mannion AF, Caporaso F, Pulkovski N dan Sprottet H. 2012. Spine Stabilisation Exercises in the Treatment of Chronic Low Back Pain: A Good Clinical Outcome is not Associated with Improved Abdominal Muscle Function. European Spine Journal, 21(7): 13011310. [Cited 2019 July 8]. Available from:

https://www.ncbi.nlm.nih.gov/pmc/article s/PMC3389103/pdf/586_2012_Article_2 155.pdf

16. Luomajoki HA, Bonet, Beltran MB, Careddu S dan Bauer CM. 2018. Effectiveness of Movement Control Exercise on Patients with Non-Specific Low Back Pain and Movement Control Impairment: A Systematic Review and Meta-analysis, Musculoskeletal Science and Practice, Aug 36:1-11. [Cited 2019 Mar. 3]. Available from:

https://www.ncbi.nlm.nih.gov/pubmed/29 631119

17. Smallwood J, Brown KS, Baird B, Mrazek MD, Franklin MS dan Schooler JW. 2012. Insulation for Daydreams: A Role for Tonic Norepinephrine in the Facilitation of Internally Guided Thought. PLoS one , 7(4):e33706. [Cited 2018 Dec. 1]. Available from:

https://www.ncbi.nlm.nih.gov/pmc/article s/PMC4295260/

18. Meier ML, Stampfli P, Vranal A, Humhreysl BK, Seifritz E dan HotzBoendermaker S. 2016. Neural Correlates 
of Fear of Movement in Patients with Chronic Low Back Pain vs. Pain-Free Individuals. Frontiers in Human Neuroscience, 10:386. [Cited 2018 Dec. 1]. Available from:

https://www.frontiersin.org/articles/10.33 89/fnhum.2016.00386/full

19. Schmalzl L, Crane-Godreau MA dan Payne P. 2014. Movement-based Embodied Contemplative Practices: Definitions and Paradigms. Frontiers in Human Neuroscience, 10: 205. [Cited 2018 Dec. 20]. Available from:

https://www.frontiersin.org/articles/10.33 89/fnhum.2014.00205/full 